\title{
Carbonyl compounds emitted by a diesel engine fuelled with diesel and biodiesel-diesel blends: Sampling optimization and emissions profile
}

\author{
Lílian Lefol Nani Guarieiro a, Pedro Afonso de Paula Pereira ${ }^{\mathrm{a}, \mathrm{d}}$, Ednildo Andrade Torres ${ }^{\mathrm{b}, \mathrm{d}}$, \\ Gisele Olimpio da Rocha ${ }^{\mathrm{c}, \mathrm{d}}$, Jailson B. de Andrade ${ }^{\mathrm{a}, \mathrm{d}, *}$ \\ a Universidade Federal da Bahia, Instituto de Química, 40170-290 Salvador-BA, Brazil \\ ${ }^{\mathrm{b}}$ Universidade Federal da Bahia, Escola Politécnica, 40210-730 Salvador-BA, Brazil \\ ${ }^{\mathrm{c}}$ Instituto Multidisciplinar em Saúde - UFBA, Campus Anísio Teixeira, 45055-090 Vitória da Conquista-BA, Brazil \\ ${ }^{\mathrm{d}}$ Centro Interdisciplinar de Energia e Ambiente - CIEnAm, Universidade Federal da Bahia, Canela, 40110-040 Salvador-BA, Brazil
}

\section{A R T I C L E I N F O}

\section{Article history:}

Received 29 April 2008

Received in revised form 25 July 2008

Accepted 25 July 2008

\section{Keywords:}

Biodiesel

Acrolein

Carbonyl compounds

Diesel

Vehicular emissions

CC emission factors

Biofuels

\begin{abstract}
A B S T R A C T
Biodiesel is emerging as a renewable fuel, hence becoming a promising alternative to fossil fuels. Biodiesel can form blends with diesel in any ratio, and thus could replace partially, or even totally, diesel fuel in diesel engines what would bring a number of environmental, economical and social advantages. Although a number of studies are available on regulated substances, there is a gap of studies on unregulated substances, such as carbonyl compounds, emitted during the combustion of biodiesel, biodieseldiesel and/or ethanol-biodiesel-diesel blends. CC is a class of hazardous pollutants known to be participating in photochemical smog formation. In this work a comparison was carried out between the two most widely used CC collection methods: C18 cartridges coated with an acid solution of 2,4-dinitrophenylhydrazine (2,4-DNPH) and impinger bottles filled in 2,4-DNPH solution. Sampling optimization was performed using a $2^{2}$ factorial design tool. Samples were collected from the exhaust emissions of a diesel engine with biodiesel and operated by a steady-state dynamometer. In the central body of factorial design, the average of the sum of CC concentrations collected using impingers was $33.2 \mathrm{ppmV}$ but it was only $6.5 \mathrm{ppmV}$ for $\mathrm{C} 18$ cartridges. In addition, the relative standard deviation (RSD) was $4 \%$ for impingers and $37 \%$ for C18 cartridges. Clearly, the impinger system is able to collect CC more efficiently, with lower error than the C18 cartridge system. Furthermore, propionaldehyde was nearly not sampled by C18 system at all. For these reasons, the impinger system was chosen in our study. The optimized sampling conditions applied throughout this study were: two serially connected impingers each containing $10 \mathrm{~mL}$ of $2,4-\mathrm{DNPH}$ solution at a flow rate of $0.2 \mathrm{~L} \mathrm{~min}^{-1}$ during $5 \mathrm{~min}$. A profile study of the C1-C4 vapor-phase carbonyl compound emissions was obtained from exhaust of pure diesel (B0), pure biodiesel (B100) and biodieseldiesel mixtures (B2, B5, B10, B20, B50, B75). The $\Sigma$ CC of the emission concentrations were $20.5 \mathrm{ppmV}$ for $\mathrm{B} 0$ and $15.7 \mathrm{ppmV}$ for B100. When considering fuel blends, the measured $\Sigma C C$ were $21.4 \mathrm{ppmV}, 22.5 \mathrm{ppmV}, 20.4 \mathrm{ppmV}, 14.2 \mathrm{ppmV}, 11.4 \mathrm{ppmV}$ and 14.7 ppmV, respectively, for B2, B5, B10, B20, B50 and B75. Among the target CC, both formaldehyde and acetaldehyde were the major contributors to the observed total CC levels. Except for acrolein and formaldehyde, all CC showed a clear trend of reduction in the emissions from B2 to B100 (40\% reduction, on average). Both individual and total CC emission factors ( $\mathrm{pg} \mathrm{g}^{-1}$ of fuel burnt) were calculated for all tested biodiesel-diesel
\end{abstract}

\footnotetext{
* Corresponding author. Universidade Federal da Bahia, Instituto de Química, 40170-290 Salvador-BA, Brazil. Tel./fax: +55 7132375524 .

E-mail address: jailsong@ufba.br (J.B. de Andrade).
} 
blends. The lowest total CC emission factor (2271 $\mathrm{pg} \mathrm{g}^{-1}$ ) was found when B50 was used; the individual emission factors determined ( $\mathrm{pg} \mathrm{g}^{-1}$ ) were: 539.7 (formaldehyde), 1411 (acetaldehyde), 30.83 (acrolein), and 310.7 (propionaldehyde).

(c) 2008 Elsevier Ltd. All rights reserved.

\section{Introduction}

Vehicular emission in many urban centers around the world and also in Brazil is being considered one of the most important sources of air toxics to the atmosphere, both in the vapor- and particle-phases (Corrêa and Arbilla, 2006; Manoli et al., 2002; Azimi et al., 2005; Turrio-Baldassarri et al., 2004; de Andrade et al., 1993, 1995, 1998). Both phases contain carcinogenic substances, such as carbonyl compounds (e.g. formaldehyde), light aromatic hydrocarbons (e.g. benzene), PAHs, and nitro-PAHs (Turrio-Baldassarri et al., 2004; Corrêa and Arbilla, 2006; Pang et al., 2006; Bikas and Zervas, 2007; de Andrade et al., 1995, 1998). Carbonyl compounds (CC) are ubiquitous constituents of the urban atmosphere and well known to participate in photochemical smog formation. They are important precursors of ozone and other hazardous substances, such as peroxylacylnitrate (PAN) (Tanner et al., 1988; Grosjean et al., 1993; Carter, 1995; Gaffney et al., 1997; de Andrade et al., 1998).

In urban centers, CC are mainly emitted by anthropic sources such as vehicles. Even though diesel fuelled heavyduty vehicles represent only $5.93 \%$ of the Brazilian fleet ( $\sim 2.5$ millions of trucks and buses) their emission factors are higher than those of light-duty vehicles; their consumption represents $44 \%$ of the total fuel consumption in Brazil, totalizing 39 million cubic meters (Corrêa and Arbilla, 2006 and references therein).

Nowadays, the increase of vehicular fleet, the demand of energy production and the decrease of fossil fuel sources, and climate change reflect the search for both affordable and renewable fuels. Biodiesel, an emerging and renewable fuel, is becoming a promising alternative to fossil fuels. It is an oxygenated fuel made from vegetable oils and animal fats by conversion of the triglyceride fats to esters via transesterification reaction (Pinto et al., 2005; Pang et al., 2006). Biodiesel can form blends with diesel in any ratio, and thus could replace partially, or even totally, diesel in combustion engines what would bring a number of environmental, economical and social advantages. Regarding environmental concerns, many studies have shown that pure biodiesel, biodiesel-diesel and biodieselethanol-diesel blends may reduce emissions of regulated substances $\left(\mathrm{NO}_{x}, \mathrm{CO}, \mathrm{CO}_{2}, \mathrm{SO}_{x}\right.$, total hydrocarbons and particulate matter) (Dorado et al., 2003; Shi et al., 2006; Pang et al., 2008). However, there is an increasing interest in studying emissions of some unregulated substances, such as carbonyl compounds, PAHs, nitro-PAHs and other toxics that are of concern from both environmental and human health aspects (Pinto et al., 2005).

Concerning CC emissions, there are some divergences when considering the results obtained using pure diesel and biodiesel blends. Depending upon the author biodiesel could contribute to increase or decrease in the CC emissions (Bikas and Zervas, 2007; Turrio-Baldassarri et al., 2004;
Corrêa and Arbilla, 2008; Lev-On et al., 2002; Durbin et al., 1999). Nevertheless, the comparison of those studies is not trivial since different authors have used different biofuel sources, engines, and especially, different sampling methodologies or protocols.

Historically, carbonyl compounds have been basically sampled in two ways: by impinger bottles (wet collection) and by coated $\mathrm{C} 18$ cartridges (dry collection). In both ways of sampling an acidified solution of 2,4-dinitrophenylhydrazine (2,4-DNPH) is employed, which reacts quantitatively with the carbonyl compounds. The resulting CC-hydrazone derivatives are then separated and quantified by highperformance liquid chromatography. Nowadays, many researchers have preferred the employment of C18 cartridges rather than impingers, perhaps because cartridges are easier to transport and use (Feng et al., 2005; Shi et al., 2006; Rubio et al., 2006; Tang et al., 2007; Chi et al., 2007; Corrêa and Arbilla, 2008; Peng et al., 2008), although the latter remains in use (Bikas and Zervas, 2007).

This study has two main objectives: (i) to assess the most efficient method for sampling vapor CC emitted by diesel engines fuelled with diesel and diesel-biodiesel blends, and (ii) to study the emission patterns of gaseous (C1-C4) CC for the following fuel compositions: pure diesel (B0), pure biodiesel (B100) and biodiesel-diesel blends (B2, $\mathrm{B} 5, \mathrm{~B} 10, \mathrm{~B} 20, \mathrm{~B} 50$, and B75). In order to optimize the sampling method we have used a multivariate approaching by using factorial design, utilizing an engine fuelled with biodiesel (B100) settled on a dynamometer. This optimized methodology was adopted to study CC emission profiles of different diesel-biodiesel blends.

\section{Experimental}

\subsection{Fuels and chemicals}

Two kinds of biodiesels were used in this work: (i) soybean oil biodiesel, which was used in the optimization step of the sampling method and (ii) residual oil biodiesel, used in the carbonyl compound emission studies. Certified methyl soybean biodiesel (SB) was kindly donated by Comanche Inc. (Comanche Biocombustíveis da Bahia Ltda, Centro Industrial de Aratu, Simões Filho, Bahia, Brazil). Methyl residual oil biodiesel (RB) was produced by the biodiesel pilot plant of UFBA; commercial pure diesel oil was purchased from Petrobrás (Petrobrás Distribuidora, Brazil). The specifications of the SB and RB fuels were determined following EN 14105 (Table 1).

All chemicals employed in this study were either of analytical or spectroscopic/chromatographic grade. Formaldehyde, acetaldehyde, propionaldehyde, acrolein, butyraldehyde and 2,4-dinitrophenylhydrazine standards were purchased from Sigma-Aldrich (Sigma-Aldrich Inc., USA) and then their respective 2,4-dinitrophenylhydrazones 
Table 1

Fuel specifications for SB (soy bean oil) and RB (residual oil) biodiesels

\begin{tabular}{|c|c|c|}
\hline Characteristics & Soybean biodiesel & Residual biodiesel \\
\hline Monodiacylglycerol $(\%, w)$ & 0.0673 & 0.1243 \\
\hline Diacylglycerol $(\%, \mathrm{w})$ & 0.0055 & 0.0737 \\
\hline Triacylglycerol $(\%, \mathrm{w})$ & 0.0087 & 0.0919 \\
\hline Free glycerol $(\%, \mathrm{w})$ & $\mathrm{nd}^{\mathrm{a}}$ & 0.0056 \\
\hline Total glycerol $(\%, \mathrm{w})$ & 0.0815 & 0.2955 \\
\hline $\mathrm{IA}, \mathrm{mg} \mathrm{KOH} \mathrm{g}^{-1}$ & nab & 0.39 \\
\hline Viscosity (cSt, $\left.40^{\circ} \mathrm{C}\right)$ & 4.20 & 5.76 \\
\hline Fulgor index $\left({ }^{\circ} \mathrm{C}\right)$ & 164 & 178 \\
\hline Ashes (\%) & $n a^{b}$ & 0.012 \\
\hline Appearance & Darkish, no impurities & Translucent, limpid \\
\hline Density $\left(\mathrm{g} \mathrm{mL}^{-1}, 20^{\circ} \mathrm{C}\right)$ & $n a^{b}$ & 0.893 \\
\hline Ester yield (\%) & $n a^{b}$ & 99.7 \\
\hline
\end{tabular}

a $\mathrm{nd}=$ Not detected.

b na $=$ Not available

were produced and purified in our laboratory. Spectroscopic and chromatographic grade acetonitrile and methanol were purchased from J.T. Baker (J.T. Baker, USA); deionised water was obtained from a NanoPure Diamond (USA) water purification system.

\subsection{Optimization of the CC sampling conditions}

As an initial step, a screening $2^{2}$ factorial design (Statistica 6.0 software pack, Statsoft, USA) was performed to evaluate significant variables involved in the CC sampling. Three replicates were performed in the central body of factorial design in order to qualify the experimental error. The significant variables, at 95\% of confidence level, found by screening experimental design, were both flow rate and sampling time. Experimental domains for flow rate and sampling time ranged from 0.2 to $0.6 \mathrm{~L} \mathrm{~min}^{-1}$ and from 5 to 10 min, respectively (Table 2 ).

Vapor-phase C1-C4 carbonyl compounds were sampled from exhaust of an internal combustion engine fuelled with SB fuel. A comparison of two different gaseous carbonyl compounds sampling methods was performed by using impinger bottle filled with $10 \mathrm{~mL}$ 2,4-DNPH solution (wet collection) and a C18 coated-cartridge (C18 Sep-Pak Silica Gel Cartridge, Waters-Millipore, USA) impregnated with 2,4-DNPH (dry collection). A detailed account of the preparation and purification of the 2,4-DNPH solution is described elsewhere (de Andrade et al., 1996). In order to reach quantitative samplings and avoid breakthrough during CC collection, each sampling system consisted of two samplers in line (Fig. 1). In the dry sampling, we used two C18 Sep-Pak cartridges in line (Fig. 1), coated with $5 \mathrm{~mL}$ of 2,4-DNPH solution (according to procedure reported by de Andrade and Miguel, 1985; Grosjean et al., 1993; de Andrade et al., 1998). After sampling, the cartridges were eluted with $5 \mathrm{~mL}$ of acetonitrile into amber bottles and stored under refrigeration at $-4{ }^{\circ} \mathrm{C}$ until analysis. CC samples (cartridges

Table 2

Experimental levels employed for screening design

\begin{tabular}{lllc}
\hline Variables & \multicolumn{2}{l}{ Coded variables } \\
\cline { 2 - 4 } & $(-1)$ & $(0)$ & $(+1)$ \\
\hline Sampling flow rate $\left(\mathrm{L} \mathrm{min}^{-1}\right)$ & 0.2 & 0.4 & 0.6 \\
Sampling time (min) & 5.0 & 7.5 & 10 \\
\hline
\end{tabular}

and impingers) were analyzed in duplicate; 10 cartridges were used as laboratory blanks. To assess the extent of contamination through passive sampling during the collection period, three opened flasks containing each $10 \mathrm{~mL}$ 2,4-DNPH solution were left in and around the sampling system during CC collection with impingers. In the same way, when sampling with C18 cartridges, a similar procedure was followed by leaving three $\mathrm{C} 18$ cartridges impregnated with 2,4-DNPH close to collection system. In both situations, either impinger or cartridges (called field blanks) were subjected to the same conditions of samples during the same time that $\mathrm{CC}$ was being actively collected from engine exhausts (CC samples) and transported to the laboratory for analysis. No carbonyl compound was found above the limit of detection in cartridges or impingers.

\subsection{Analysis of carbonyl compounds}

Carbonyl derivatives were separated and quantified using a high-performance liquid chromatograph coupled to a UV-VIS detector system (HPLC-UV-VIS, Intralab 5100). An isocratic separation was performed with a $\mathrm{C} 18$ analytical column $(25 \mathrm{~cm} \times 4.6 \mathrm{~mm} \times 5 \mu \mathrm{m}$, Merck KGaA, Germany) using a mobile phase of $\mathrm{MeOH} / \mathrm{MeCN} / \mathrm{H}_{2} \mathrm{O}(74.5 / 0.50 / 25.0 \%$ $\mathrm{v} / \mathrm{v} / \mathrm{v}$ ) for $15 \mathrm{~min}$ at a flow rate of $1 \mathrm{~mL} \mathrm{~min}^{-1}$ and detection at $365 \mathrm{~nm}$.

The identification of the CC was done based on matching the retention time of unknown peaks with those of authentic standards (formaldehyde, acetaldehyde, acrolein, propionaldehyde/acetone and butyraldehyde hydrazones). The quantification of the identified compounds was carried out by using analytical curves made from seven levels of external standard concentrations, ranging from 0.025 to $1.5 \mu \mathrm{g} \mathrm{mL}{ }^{-1}$, for each CC. The limit of detection (LOD) was considered as $3 \times(s / a)$, where " $s$ " is the standard deviation of linear coefficient from analytical curve and " $a$ " is angular coefficient from analytical curve, adjusted to the sampling time and flow rate used during collection of samples. LODs were (ppbV): 23.4 (formaldehyde), 267 (acetaldehyde), 30.6 (acrolein), 54.9 (propionaldehyde), and 100 (butyraldehyde). All samples collected during our study presented CC levels above their respective LOD.

\subsection{Evaluation of the CC emission profile of biodiesel-diesel mixtures}

A diesel engine, Agrale ${ }^{\circledR}$, model M85, $10 \mathrm{HP}$, speed rate of $1800 \mathrm{rpm}$, operating in a stationary mode and with no loading, coupled to a steady-state dynamometer, was used for the tests. The engine's main characteristics are listed in Table 3. The following mixtures were used as engine fuel: biodiesel-diesel (B2, B5, B10, B20, B50 and B75) and pure diesel (B0), pure biodiesel (B100) as well.

\section{Results and discussion}

\subsection{Carbonyl compounds sampling methodology optimization}

The vapor-phase (C1-C4) CC sampling methodologies were tested in order to verify their efficacy for sampling 


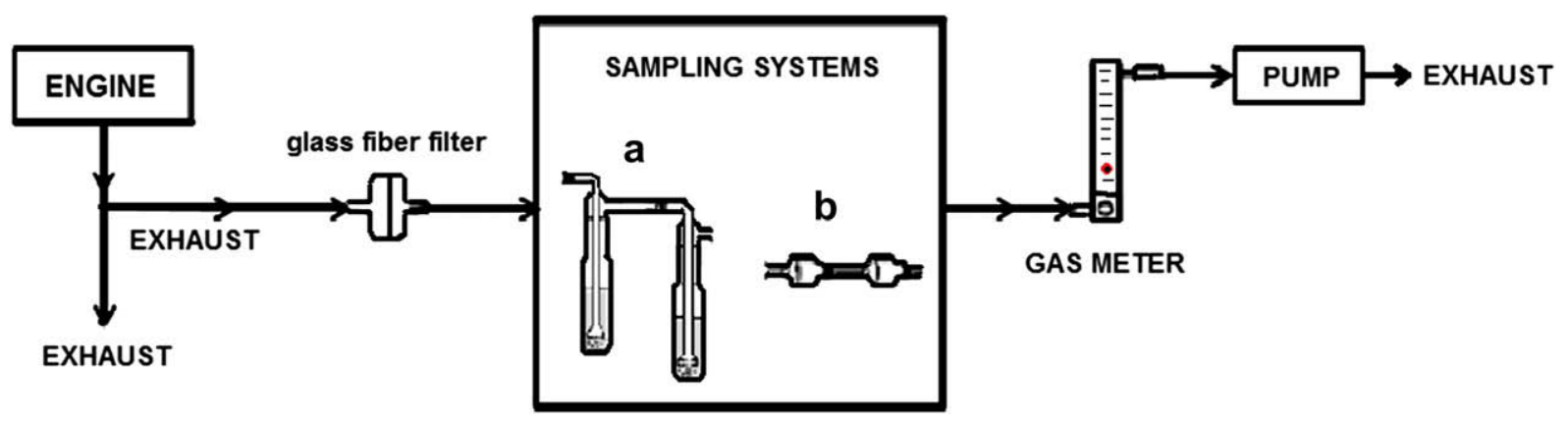

Fig. 1. Scheme of the sampling system for carbonyl compounds emission. Either (a) two impinger bottle or (b) two C18 coated-cartridges were used each time.

diesel engine exhaust. The results obtained by screening factorial design are summarized in Pareto's chart (Fig. 2). Among the studied parameters, only the sampling time was significant at a 95\% confidence level for C18 cartridges system (Fig. 2a). For the impinger system, all studied variables and their interactions (time and sampling flow rate) were significant at 95\% confidence level (Fig. 2b). Response surface obtained by central body design is illustrated in Fig. 3. When comparing C18 cartridges and impingers, the standard errors obtained by three replicates in the central point were 5.67 and 1.61 for C18 cartridges and impinger system, respectively (Fig. 4).

In the central body, the average $\Sigma C C$ concentrations determined using impingers was $33.2 \mathrm{ppmV}$ while it was only $6.5 \mathrm{ppmV}$ for C18 cartridges. Additionally, while the relative standard deviation (RSD) for impingers was $4 \%$, it was $37 \%$ for $\mathrm{C} 18$ cartridges. Furthermore, propionaldehyde was nearly not detected using the C18 system at all. Thus, the impinger bottles are able to collect CC more efficiently and with lower error than the $\mathrm{C} 18$ cartridge system. While CC samplings in indoor and outdoor ambient air using C18 cartridges coated with 2,4-DNPH may be appropriate, our results show that this system is not suitable for the conditions applied in this study at much higher concentrations. A hypothesis to explain a higher CC content collected by impingers is that this sampler provides a more humid medium (enabled by $10 \mathrm{~mL} 2,4-\mathrm{DNPH}$ solution) that is more suitable in collecting quantitatively hot turbulent freshly released exhaust from the engine than just the

Table 3

Main characteristics of the diesel engine

\begin{tabular}{ll}
\hline Characteristics & Diesel engine \\
\hline Potency NF (NBRISO 1585) Cv/kW/rpm & $30 / 22 / 3000$ \\
Maximum torque (NBRISO 1585) daNm/rpm & $7.0 / 2500$ \\
Number of cylinders & 2 verticals \\
Cylinder diameter (mm) & 90 \\
Swept volume $\left(\mathrm{cm}^{3}\right)$ & 1272 \\
Piston displacement $(\mathrm{mm})$ & 100 \\
Carter capacity (L) & 6 \\
Compression rate & $18: 1$ \\
Fuel consumption (g/kWh) & 272 \\
Feeding injection system & Direct \\
Refrigeration of the engine & Air \\
\hline
\end{tabular}

easily saturated thin film of 2,4-DNPH available onto C18 reversed phase silica particles from cartridges, reflecting in CC losses by breakthrough in the case of $\mathrm{C} 18$ cartridge use for exhaust sampling. Therefore, impingers were used throughout this study.

The response surface shows that the higher the sampling time and flow rate the higher would be the CC amount collected (Fig. 3). Meanwhile, attention should be paid to the breakthrough effect in the sampling procedure. When a sampling flow rate of $0.6 \mathrm{~L} \mathrm{~min}^{-1}$ and the sampling time of $10 \mathrm{~min}$ are applied the amount of CC collected in the second impinger represented $90 \%$ of that collected in the first one. Reducing the flow rate to $0.4 \mathrm{~L} \mathrm{~min}^{-1}$ and the sampling time to $7.5 \mathrm{~min}$, the breakthrough decreased to $60 \%$, yet it remains in a high level of CC to be present in the second impinger. Finally, at a flow rate of $0.2 \mathrm{~L} \mathrm{~min}^{-1}$, independently of sampling time (range of 5-10 min), the breakthrough was below $26 \%$, i.e. acceptable in order to minimize CC losses and insure quantitative CC collection. Despite the fact that the multivariate approach was not totally utilized for reaching the optimum conditions, it was useful for finding the best conditions, using fewer experiments. Thus, the optimized sampling conditions applied throughout this study were: two serially connected impingers containing each one $10 \mathrm{~mL}$ of 2,4-DNPH solution, with a flow rate of $0.2 \mathrm{~L} \mathrm{~min}^{-1}$ during $5 \mathrm{~min}$.

\subsection{Assessment of vapor-phase CC emitted from biodiesel- diesel blends}

The optimized method just described above was used for assessing vapor-phase C1-C4 carbonyl concentrations from a diesel engine setup onto a steady-state dynamometer. $\Sigma C C$ ranged from $20.5 \mathrm{ppmV}$ (for B0) to $15.7 \mathrm{ppmV}$ (for B100). When considering the fuel blends, the measured $\Sigma C \mathrm{C}$ were $21.4 \mathrm{ppmV}, 22.5 \mathrm{ppmV}, 20.4 \mathrm{ppmV}, 14.2 \mathrm{ppmV}$, $11.4 \mathrm{ppmV}$ and $14.7 \mathrm{ppmV}$ for B2, B5, B10, B20, B50 and B75, respectively. Such high levels found for B2-B10 were mainly observed because in these blends both formaldehyde and acetaldehyde have increased emissions (Fig. 5); they are the major contributors for those total CC levels (but they have shown decreases from B10 to B50). However, propionaldehyde and butyraldehyde have demonstrated a gradual decrease when rising biodiesel 

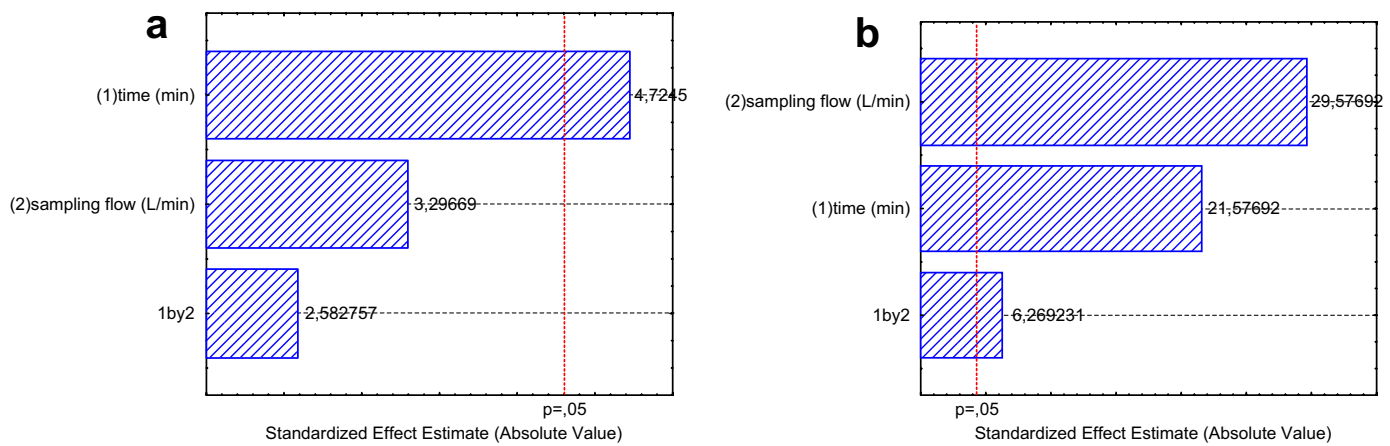

Fig. 2. Pareto chart of standardized effects of $2^{2}$ factorial design for CC concentration (ppmV). (a) C18 cartridge system, and (b) impinger system.

level in all tested fuels (from B0 to B100) while acrolein follows the opposite tendency. Acrolein released from engine exhausts with B100 (225 ppbV) is more than four times higher than that observed with pure diesel (B0) (51 ppbV).

In order to understand CC emissions in Fig. 5, it is helpful to take the following discussion. Concerning each fuel composition, it is known that pure diesel is mainly composed of aliphatic saturated hydrocarbons and aromatics with carbon number ranging from C6 through C20. Generally, tetradecane, pentadecane, and hexadecane are dominant in fossil diesel. The other straight-chain alkanes gradually decline from the dominant compounds to either higher or lower carbon numbers. Aliphatic alkanes are the main components. Branched alkanes and aromatics are present in lesser amounts (Peng et al., 2006). On the other hand, pure soybean biodiesel presents as main components linoleic acid methyl ester, oleic acid methyl ester, and palmitic acid methyl ester and, to a lesser extent, also linolenic acid methyl ester and stearic acid methyl ester. Considering that waste cooking oil is mainly soybean oil that underwent repeated thermal oxidative processes before discharging, it is reasonable to assume that residual oil biodiesel is also mainly composed of the same major methyl esters but with a higher content of minor short-chain components originated from breakdown of unsaturated fatty acids during cooking (Peng et al., 2006; da Silva and Pereira, 2008).

Combustion is an inherently oxidative process that when rigorously efficient should convert all organic matter into carbon dioxide and water. Mechanistically, when burning straight-chain alkanes (as it is found in fossil diesel) under the considered oxidative conditions, alkanes would be converted to alcohols, then to carbonyl compounds, then to carboxylic acids, then to esters, and finally to carbon dioxide (alkanes are the most reduced substances being gradually converted until the most oxidized substance - carbon dioxide). However, it is known that no engine possesses such efficiency to undergo a complete combustion. Therefore, when burning pure diesel (B0) a very special set of conditions (temperature, energy, compression rate, among others) would be necessary to convert diesel totally into carbon dioxide. In face of incomplete combustion of diesel, there are conditions just to produce other toxic chemicals (and emit them to atmosphere) such as carbonyl compounds and others as well (Schauer et al., 1999). On the other hand, when burning pure biodiesel (B100), it is a reasonable assumption that conditions would be more prone for conversion of esters into carbon dioxide. Under this point of view, biodiesel burning is probably more complete than diesel combustion.
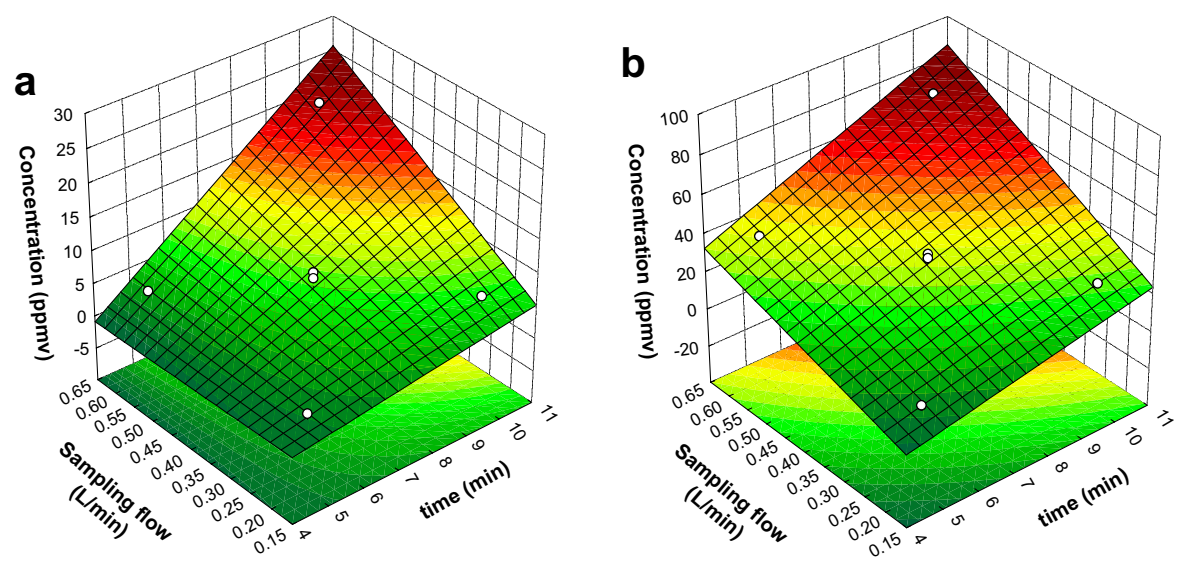

Fig. 3. Response surface of factorial planning $2^{2}$ : (a) C18 cartridge system, and (b) impinger system. 


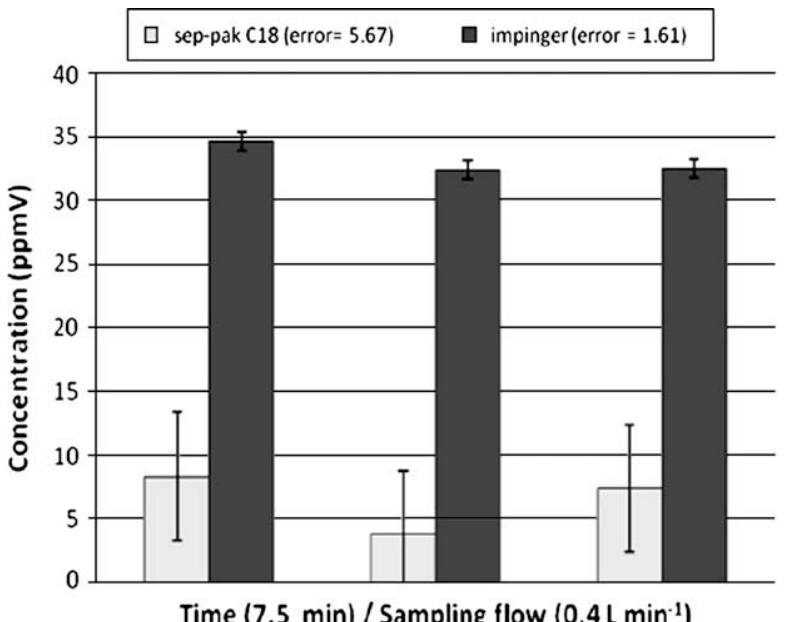

Fig. 4. Average values (triplicates) in the central body for both C18 cartridges and impingers. Bars indicate standard error.

Addition of different volumes of biodiesel to diesel would provoke decreases in the CC emission levels. Since in B2 through B10 the relative quantity of biodiesel to diesel is low; there was not an observable reduction in the $\mathrm{CC}$ emissions. However, reduction is clear in B50. Probably, with this blend there is enough biodiesel content to favor a more complete combustion and a decrease in CC emissions. There is a small increase in B75 and B100 emission levels due to either of the following reasons: (i) some fluctuation common to random error in acquisition of data, or (ii) any other mechanism of formation of $\mathrm{CC}$ that prevails in those contents of biodiesel-to-diesel.

The process of heating biodiesel inside the combustion chamber, along with oxygen, can generate several types of compounds, through reactions such as oxidation and polymerization, since it is basically an ester mixture of saturated and nonsaturated fatty acids. These products may include secondary oxidation products such as volatile and non-volatile carbonyl compounds, cyclic fatty acid monomers and polymerization products. Among these, aldehydes seem to be the most important since they are the most abundant when compared to the other possible products. Besides, as the biodiesel used in these tests was produced from fried oil, it is reasonable to suppose that it had already a significant amount of CC, from the thermal oxidative processes which occur during the frying of meats.

Both formaldehyde and acetaldehyde were the CC emitted in the highest levels for all assessed fuel/fuel blends. When compared to diesel, formaldehyde emission is increased for all mixtures except for B50 while acetaldehyde emission is decreased for all mixtures except for B5. Residual oil biodiesel has many short-chain chemicals that favor formation of the shortest chain carbonyl (namely formaldehyde) during combustion but this trend was not observed with those longer chain CC which have shown a gradual emission decrease with rising biodiesel quantity in the fuel being burnt because they are mainly originated from diesel alkane combustion. On the other hand, acrolein has its emission increased since it has mostly been produced by oxidation of glycerol residues and other fatty acid residues present in the biodiesel (Table 1) (da Silva and Pereira, 2008).

Our results discussed up to this point, bring in this way, some criticism about discordant results reported in the literature. Concerning a few studies related to CC emissions from diesel and biodiesel blends available, TurrioBaldassarri et al. (2004), Pang et al. (2006) and Corrêa and Arbilla (2008) have reported increases (about 20-25\%) of CC levels in engine exhaust when adding biodiesel to diesel, while Peng et al. (2008) have found decreases in CC emissions and Schauer et al. (1999) have reported that $60 \%$ of the gas-phase organic compound mass emissions from fossil diesel in a medium duty neat diesel trucks (mainly formaldehyde, acetaldehyde and acetone but significant quantities of propionaldehyde, butanone and crotonaldehyde). Furthermore, Turrio-Baldassarri et al. (2004) and Corrêa and Arbilla (2008) justify CC emission increases by the high content of oxygen from methyl esters in the biodiesel but this essentially cannot occur due to oxidative media

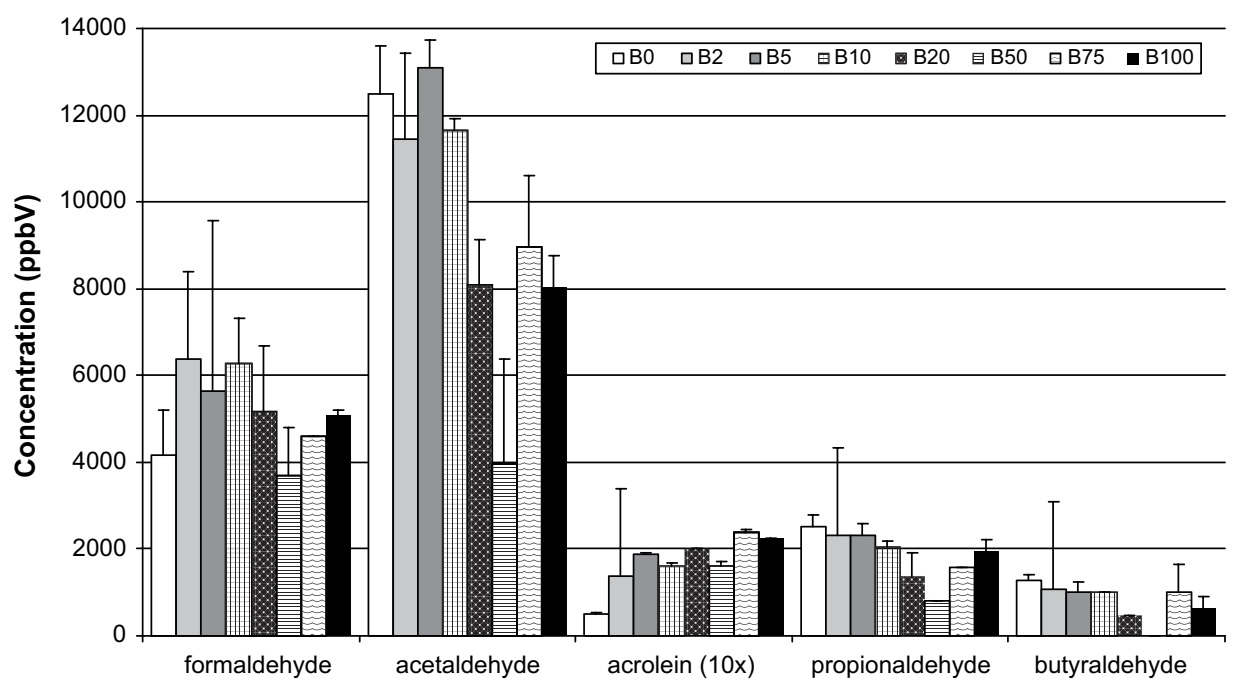

Fig. 5. Individual CC (ppmV) emitted in the exhaust gases of B0, B2, B5, B10, B20, B50, B75 and B100 (residual oil biodiesel). Bars indicate standard deviation. 


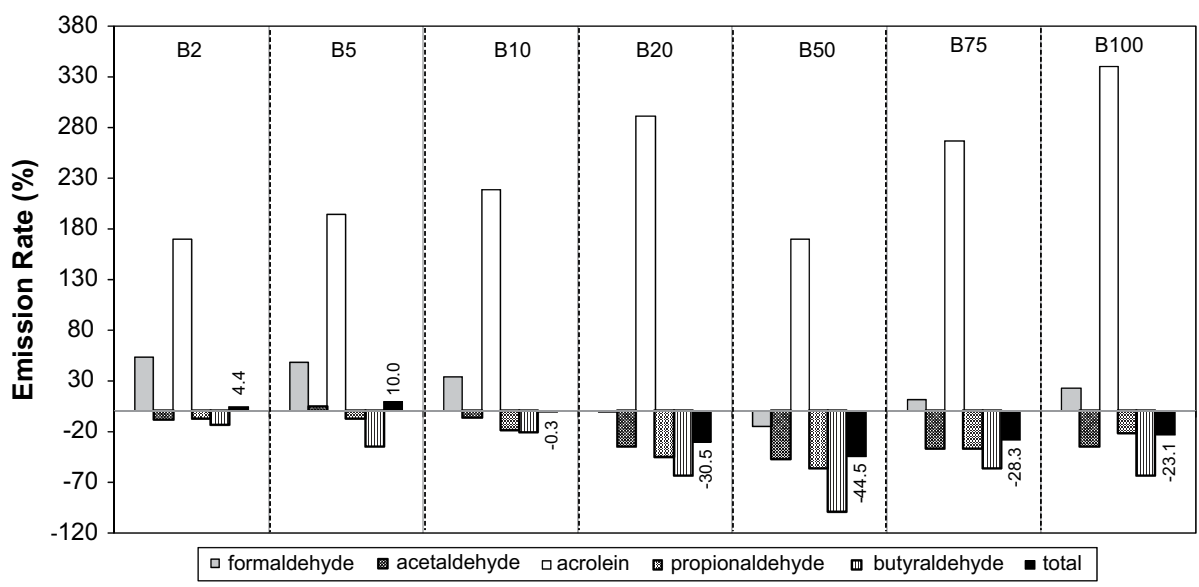

Fig. 6. Decreases in the emission rate (\%) of both individual and total CC by employment of B2, B5, B10, B20, B50, B75 and B100 (residual oil biodiesel) mixes in relation to pure fossil diesel.

during combustion in the engines. Also, it is noted that all studies have used C18 cartridges coated with 2,4-DNPH and we have shown in the first part of this study that it is not an appropriate method of sampling CC since it undergoes significant losses by breakthrough. Despite all these, further studies are necessary for a better understanding of this topic.

Fig. 6 shows CC total concentrations released from each blend of fuel, pure biodiesel and/or pure diesel. Any significant abatement of total CC emission starts at B20 going through B75. This result is comparable with those obtained by Peng et al. (2008) who also observed a decrease when using B20, though Corrêa and Arbilla (2008) have found that the CC emissions from B20 were higher than those from pure diesel. These discordant results, in addition to what we have discussed above, may result from a different kind of biodiesel since the former have used waste cooking oil and the latter castor oil, as well as different analytical methodologies used.

In Fig. 6 acrolein has presented considerable increase in its emission rate $(170-340 \%$ by acrolein for B2-B100 in relation to pure diesel) as well as formaldehyde has presented an increase in its emission rate (22-53\%) for all mixtures, except for B20 and B50. It is interesting to note that formaldehyde is considered carcinogenic to humans by IARC (IARC, 2004) and a reduction in air levels would be desired, not an increase as observed for B2-B10 and B75B100 mixtures (B2 is already implanted in Brazil by Government Decree). Nowadays, in Brazil, the B2 mixture is commercially available in any Petrobrás petrol station, but the Brazilian Government plans to adopt the B5 mix in the coming years. Furthermore, except for acrolein, we observed a trend in the reduction of CC beginning only from B20 mixture (total CC emission rate is reduced by $30.5 \%$ in relation to original diesel) until B75. Propionaldehyde and butyraldehyde have shown a clear trend of reduction of their emissions with the raise of the biodiesel content in the tested mixtures. Propionaldehyde reduction ranged from $8 \%$ to $56 \%$; for butyraldehyde the reduction was $14-99 \%$, depending on the mixture. Therefore, in terms of vapor-phase light CC emissions, there will be a significant reduction effect when B20 or, more appropriately, B50 is adopted.

Table 4 shows both individual and total CC emission factor in terms of quantity of CC (unit in $\mathrm{pg} \mathrm{g}^{-1}$ ) emitted per liter of fuel burnt for all tested biodiesel-diesel blends. In Table 4 is shown that the lowest total CC emission factor $\left(2271 \mathrm{pg} \mathrm{g}^{-1}\right.$ ) was achieved with B50. For B50 individual emission factors ( $\mathrm{pg} \mathrm{g}^{-1}$ ) were: 539.7 (formaldehyde), 1411 (acetaldehyde), 30.83 (acrolein) and 310.7 (propionaldehyde).

\section{Conclusions}

Our results highlight that in spite of the fact that while sampling CC emitted from diesel engines using C18 cartridges (dry sampling) has been widely used by several

Table 4

Individual and total CC emission factor according to biodiesel-diesel mixtures (units in $\mathrm{pg} \mathrm{g}^{-1}$ )

\begin{tabular}{|c|c|c|c|c|c|c|}
\hline Mixture & Formaldehyde & Acetaldehyde & Acrolein & Propionaldehyde & Butyraldehyde & $\Sigma C C$ \\
\hline B0 & 631.9 & 2677 & 13.93 & 710.5 & 445.9 & 4479 \\
\hline B2 & 972.2 & 2452 & 37.60 & 657.2 & 382.7 & 4501 \\
\hline B5 & 936.7 & 2804 & 40.98 & 657.2 & 287.8 & 4726 \\
\hline B10 & 848.1 & 2494 & 44.36 & 577.2 & 351.1 & 4315 \\
\hline B20 & 624.8 & 1735 & 54.50 & 390.7 & 161.3 & 2966 \\
\hline B50 & 539.7 & 1411 & 30.83 & 310.7 & $\mathrm{nd}^{\mathrm{a}}$ & 2271 \\
\hline B75 & 702.8 & 1664 & 51.12 & 444.0 & 192.9 & 3055 \\
\hline B100 & 773.7 & 1721 & 61.26 & 550.6 & 161.3 & 3267 \\
\hline
\end{tabular}

\footnotetext{
a $\mathrm{nd}=$ Not detected.
} 
researchers, the impinger system (wet sampling) consistently collects gas-phase light CC more efficiently. For this reason, wet sampling was the chosen collection method for CC measurement, with flow rate and sampling time conditions being optimized as $0.2 \mathrm{~L} \mathrm{~min}^{-1}$ and $5 \mathrm{~min}$, respectively.

In our study of CC profile emissions from different biodiesel-diesel mixtures, formaldehyde and acetaldehyde were the $\mathrm{CC}$ which have presented the highest emission levels. Acrolein increased for all blends while formaldehyde increased for all blends except B20 and B50. When considering total CC emissions, there is a consistent concentration decrease beginning at B20 up to B100 blends. These results show that the government's intent of adding $2 \%$ of biodiesel to commercial diesel (B2) followed by a future rise to B5 will not significantly lead to a decrease in CC emissions - since decreases become evident only at B20 or, more appropriately, B50 mixtures - but will significantly increase individual emissions of formaldehyde and acrolein.

\section{Acknowledgements}

We thank the following Brazilian agencies for funding: CNPq, FAPESB, CAPES, FINEP, ANEEL, PRONEX, and RECOMBIO. Our thanks also go to our M.Sc. student Danilo C. Santos for helpful assistance during the samplings. Thanks also go to Dr. A.H. Miguel for helpful discussions and to two anonymous referees for their valuable comments.

\section{References}

de Andrade, J.B., Pinheiro, H.L.C., Andrade, M.V., 1993. Determination of formaldehyde and acetaldehyde associated to atmospheric aerosols by HPLC. International Journal of Environmental Analytical Chemistry 52, 49-56.

de Andrade, J.B., Pinheiro, H.L.C., Andrade, M.V., 1995. The formaldehyde and acetaldehyde content of atmospheric aerosol. Journal of the Brazilian Chemical Society 6, 287-290.

de Andrade, J.B., Reis, J.O.N., Reboucas, M.V., Pinheiro, H.L.C., de Andrade, M.V., 1996. Determination of formaldehyde and acetaldehyde in drinking water and alcoholic beverages by high performance liquid chromatography (HPLC). Quimica Analitica 15, 144-147.

de Andrade, J.B., Andrade, M.V., Pinheiro, H.L.C., 1998. Atmospheric levels of formaldehyde and acetaldehyde and their relationship with the vehicular fleet composition in Salvador, Bahia, Brazil. Journal of the Brazilian Chemical Society 9, 219-223.

de Andrade, J.B., Miguel, A.H., 1985. Determination of carbonylcompounds in exhaust-gases from alcohol-fueled vehicles equipped with 3-way catalytic-converters. International Journal of Environmental Analytical Chemistry 21, 229-237.

Azimi, S., Rocher, V., Muller, M., Moilleron, R., Thevenot, D.R., 2005 Sources, distribution and variability of hydrocarbons and metals in atmospheric deposition in an urban area (Paris, France). Science of the Total Environment 337, 223-239.

Bikas, G., Zervas, E., 2007. Nonregulated Pollutants emitted from Euro 3 Diesel Vehicles as a function of their mileage. Energy and Fuels 21, 2731-2736.

Carter, W.P.L. 1995. Computer modeling of environmental chamber measurements of maximum incremental reactivities of volatile organic compounds. Atmospheric Environment 29, 2513-2527.

Chi, Y., Feng, Y., Wen, S., Lü, H., Yu, Z., Zhang, W., Sheng, G., Fua, J., 2007. Determination of carbonyl compounds in the atmosphere by DNPH derivatization and LC-ESI-MS/MS detection. Talanta 72, 539-545.

Corrêa, S.M., Arbilla, G., 2006. Aromatic hydrocarbons emissions in diesel and biodiesel exhaust. Atmospheric Environment 40, 6821-6826.
Corrêa, S.M., Arbilla, G., 2008. Carbonyl emissions in diesel and biodiesel exhaust. Atmospheric Environment 42, 769-775.

Dorado, M.P., Ballesteros, E., Arnal, J.M., Gómez, J., López, F.J., 2003. Exhaust emissions from a diesel engine fueled with transesterified waste olive oil. Fuel 82, 1311-1315.

Durbin, T., Collins, J.R., Norbeck, J., Smith, M.R., 1999. Evaluation of the effects of alternative diesel fuel formulations on exhaust emission rates and reactivity - final report for the south coast air quality management district under contract no. 98102, South Coast Air Quality Management District, DiamondBar, CA, 68 pp.

Feng, Y., Wen, S., Chen, Y., Wang, X., Lü, H., Bi, X., Sheng, G., Fu, J., 2005. Ambient levels of carbonyl compounds and their sources in Guangzhou, China. Atmospheric Environment 39, 1789-1800.

Gaffney, J.S., Marley, N.A., Martin, R.S., Dixon, R.W., Reyes, L.G., Popp, C.J., 1997. Potential air quality effects of using ethanol-gasoline fuel blends: a field study in Albuquerque, New Mexico. Environmental Science \& Technology 31, 3053-3061.

Grosjean, D., Williams II, E.L., Grosjean, E., 1993. Peroxyacyl nitrates at southern California mountain forest locations. Environmental Science \& Technology 27, 110-121.

IARC, International Agency for Research on Cancer, Press Release n\# 154 from 15 June 2004. Available from www.iarc.fr/ENG/Press_Releases/ archives.pr153a.html (accessed 23.03.08).

Lev-On, M., LeTavec, C., Uihlein, J., Kimura, K., Gautam, M., Thompson, G.J., Wayne, W.S., Clark, N., Zielinska, B., Chatterjee, S., 2002. Speciation of organic compounds from the exhaust of trucks and buses: effect of fuel and after-treatment on vehicle emission profiles. SAE Technical Paper SAE, Warrendale, PA, 01, 2873.

Manoli, E., Voutsa, D., Samara, C., 2002. Chemical characterization and source identification/apportionment of fine and coarse air particles in Thessaloniki, Greece. Atmospheric Environment 36, 949-961.

Pang, X., Shi, X., Mu, Y., He, H., Shuai, S., Chen, H., Li, R., 2006. Characteristics of carbonyl compounds from a diesel-engine using biodieselethanol-diesel as fuel. Atmospheric Environment 40, 7057-7065.

Pang, X., Mu, Y., Yuan, J., He, H., 2008. Carbonyl emission from ethanolblended gasoline and biodiesel-ethanol-diesel used in engines. Atmospheric Environment 42, 1349-1358.

Peng, C.-Y., Lan, C.-H., Dai, Y.-T., 2006. Speciation and quantification of vapor phases in soy biodiesel and waste cooking oil biodiesel. Chemosphere 65, 2054-2062.

Peng, C., Yang, H., Lan, C., Chien, S., 2008. Effects of the biodiesel blend fuel on aldehyde emissions from diesel engine exhaust. Atmospheric Environment 42, 906-915.

Pinto, A.C., Guarieiro, L.L.N., Rezende, M.J.C., Ribeiro, N.M., Torres, E.A., Lopes, W.A., Pereira, P.A.P., de Andrade, J.B., 2005. Biodiesel: an overview. Journal of the Brazilian Chemical Society 16, 1313-1330.

Rubio, M.A., Zamorano, N., Lissi, E., Rojas, A., Gutiérrez, L., Von Baer, D., 2006. Volatile carbonylic compounds in downtown Santiago, Chile. Chemosphere 62, 1011-1020.

Schauer, J.J., Kleeman, M.J., Cass, G.R., Simoneit, B.R.T., 1999. Measurements of emissions from air pollution sources. 2. C1 through C30 organic compounds from medium duty diesel trucks. Environmental Science \& Technology 33, 1578-1587.

Shi, X, Pang X, Mu, Y, He, H., Shuai, S., Wang J., Chen, H. Li, R, 2006. Emission reduction potential of using ethanol-biodiesel-diesel fuel blend on a heavy-duty diesel engine. Atmospheric Environment 40, 2567-2574.

da Silva, T.O., Pereira, P.A.de P., 2008. Influence of time, surface-to-volume ratio, and heating process (continuous or intermittent) on the emission rates of selected carbonyl compounds during thermal oxidation of palm and soybean oils. Journal of Agricultural and Food Chemistry 56, 3129-3135.

Tang, S., Frank, B.P., Lanni, T., Rideout, G., Meyer, N., Beregszaszy, C., 2007. Unregulated emissions from a heavy-duty diesel engine with various fuels and emission control systems. Environmental Science \& Technology 41, 5037-5043.

Tanner, R.L., Miguel, A.H., de Andrade, J.B., Gaffney, J.S., Streit, G.E., 1988. Atmospheric chemistry of aldehydes-enhanced peroxyacetyl nitrate formation from ethanol-fueled vehicular emissions. Environmental Science \& Technology 22, 1026-1034.

Turrio-Baldassarri, L., Battistelli, C.L., Conti, L., Crebelli, R., de Berardis, B., Iamiceli, A.L., Gambino, M., Iannaccone, S., 2004. Emission comparison of urban bus engine fueled with diesel oil and biodiesel blend. Science of the Total Environment 327, 147-162. 